\title{
SEMINÁRIOS DE ENSINO DE HISTÓRIA: EXPERIÊNCIA DE INTEGRAÇÃO ENTRE ENSINO, PESQUISA E EXTENSÃO NA UFRB
}

\author{
HISTORY TEACHING SEMINARS: EXPERIENCE OF INTEGRATING \\ UNDERGRADUATE TEACHING, RESEARCH AND UNIVERSITY EXTENSION AT \\ UFRB
}

Leandro Antonio Almeida ${ }^{1}$

\begin{abstract}
Resumo: O objetivo deste trabalho é relatar a experiência de integração entre Ensino, Pesquisa e Extensão, através do projeto "Seminários de Ensino de História", produto de uma disciplina no curso de licenciatura em História. O planejamento da atividade ocorreu em quatro etapas: escolha do tema gerador, pesquisa dos alunos, divulgação e realização dos seminários. Uma análise dos eventos realizados mostra a tendência geral dos estudantes em pesquisar algum aspecto educacional da localidade na disciplina de graduação. Isso foi evidenciado na escolha dos temas, com a seleção de problemas voltadas para análise de suas manifestações locais, e nos formatos que priorizaram aspectos atuais da educação e projetos de intervenção. A aprendizagem acadêmica foi modificada substancialmente pela integração da aula de graduação às dimensões da pesquisa e extensão universitárias, tornando o conhecimento mais significativo.
\end{abstract}

Palavras-chave: Ensino, pesquisa, extensão. Ensino de história. Formação de professores

ABSTRACT: This paper aims to analyse integration between undergraduate teaching, research and university extension through History Teaching Seminars Projetct, done at a module of History Teaching Graduate Course. Planning was done in four steps: generetor theme choice, students research, event publicize and seminars. An analysis of the events held shows the general trend of students in researching any educational aspect of the locality in the undergraduate course. The evidences are the choice of themes, with the selection of problems aiming the exam of local manifestations, and formats that prioritized current aspects of education and intervention projects. The academic learning was substantially modified by the integration of the undergraduate class dimensions of university research, making it the most significant knowledge.

Keywords: Undergraduate teaching, research, university extension. Teaching history. Teacher training.

1 Bacharel, Licenciado, Mestre e Doutor em História Social pela USP. Professor de Estágio Supervisionado e Ensino de História do Curso de Licenciatura em História da UFRB. Vicecoordenador do Mestrado Profissional em História da África, da Diáspora e dos Povos Indígenas da UFRB. 


\section{Introdução}

O objetivo deste trabalho é refletir sobre uma experiência de integração entre as dimensões de Ensino, Pesquisa e Extensão, através do projeto "Seminários de Ensino de História", produto do componente curricular "Ensino de História", disciplina do curso de licenciatura em História da Universidade Federal do Recôncavo da Bahia (UFRB), campus Cachoeira.

O seminário se constitui numa tentativa de escapar de um modelo de ensino superior no qual o conhecimento gerado na aula fica restrito à mesma. 0 destinatário principal das leituras e atividades é o próprio professor, nas provas e trabalhos escritos, ou, quando muito, os colegas de sala, através dos seminários ou atividades em grupo, que reproduzem e aprofundam temas do curso. Nessas avaliações, o docente verifica o grau de conhecimento do estudante dos temas e/ou daquela bibliografia. Se for considerada incorporada ao graduando no final do semestre letivo, ocorre a aprovação. Não é difícil perceber a presença, no ensino superior, da concepção "bancária" ou "tradicional", centrada na reprodução de conteúdos avaliados primordialmente por mecanismos de verificação de leituras, já fartamente criticada na educação básica.

A proposta desenvolvida a seguir concebe de maneira diversa o trabalho na graduação, entendido como espaço de criação de saberes cientificamente orientado, cujo produto, inspirado na subjetividade do aluno e em possível diálogo com a localidade, deve retornar aos sujeitos que aí vivem, dentro e fora das paredes da sala de aula e dos muros universitários. Logo, a "universidade de ideias" (SANTOS, 1999, cap. 8) começa na disciplina de graduação, o espaço principal destinado ao ensino, englobando tanto o trabalho de pesquisa quanto a extensão dos saberes produzidos na sala de aula, voltada à comunidade acadêmica, ao público escolar da região e a todos os interessados. Ao fugir do modelo centrado nas preleções, pretende-se trazer para a graduação a lógica de construção e divulgação de saberes que rege o nível da pós-graduação. Vale, assim, aquilo que Joana Neves disse a respeito do ensino superior em História: 
A questão central nessa discussão é a relação ensino-pesquisa. Essa relação, no curso superior de história, não deve ser, simplesmente, um teórico e formal tema para debates mas deve constituir em expressão das ações didáticas adotadas por todas as disciplinas do currículo. E essas ações didáticas deverão ser tais que, ao longo do curso de graduação capacitem o estudante para a produção de conhecimento nos diversos campos ou áreas da História tendo como efeito a sua qualificação para o exercício dessa relação quando, como professor, ele atuar em outros níveis de ensino (NEVES, 2005, p 80).

\section{Ensinar "Ensino de História" com Pesquisa}

Selva Guimarães Fonseca e Marcos Silva, ao pensarem a formação inicial e continuada do professor de história, ressaltam os aspectos políticos envolvidos nessa concepção de formação de professores de história voltada à pesquisa:

nas concepções críticas, a pesquisa não é apenas um elemento para melhor qualificar a formação e a prática docente, mas uma postura política de produção de saberes, transgressão, emancipação e transformação social. Na sala de aula, seja no espaço acadêmico do curso de licenciatura, seja na educação básica, a pesquisa é estratégica para a formação crítica dos sujeitos (FONSECA e SILVA, 2007, p. 37).

O formato já é utilizado em cursos de licenciatura e faculdades de educação. Para citar exemplos nordestinos que temos notícia, na Bahia o Laboratório de História e Geografia da UESC (Lahige) promove seminários de estágio, nos quais os estudantes elaboram palestras, oficinas e mini-cursos de extensão para professores e alunos da educação básica, além da comunidade acadêmica $^{2}$. Na UFRN a professora Crislane Barbosa Azevedo também desenvolve desde 2008 a integração ensino-pesquisa-extensão a partir dos estágios supervisionados. Na segunda etapa do seu trabalho, em 2011, planejou o "Seminário Didática e Ensino de História", integrante do projeto "História e Investigação na Escola", que

2 Ver o item "Eventos" da página do LAHIGE, http://www.uesc.br/nucleos/lahige/, acesso em $16 / 03 / 2012$. 
volta-se para a execução de atividades de investigação acerca de como se ensina e como se aprende História. As ações são desenvolvidas em escolas da rede pública de ensino do Rio Grande do Norte. Tem como público-alvo os licenciandos do curso de História e objetiva contribuir para a formação de profissionais competentes, críticos e criativos para o futuro exercício da docência. A formação acadêmica aqui defendida busca transcender o tradicional espaço da sala de aula e articular-se com diferentes dimensões da realidade, inserindo alunos de graduação em experiências reais junto a variadas pessoas portadoras de diferentes atribuições dentro de uma comunidade escolar. Construir a identidade do professor com base na contribuição para a promoção da cultura da pesquisa e da extensão, além do ensino, é o objetivo deste projeto (AZEVEDO, 2012 e 2011).

Como no currículo da UFRB os estágios concentram-se nos semestres finais do curso, pretendemos iniciar os alunos na pesquisa na área antes desse momento formativo. Escolhemos "Ensino de História" (68 hs) para testar a relação ensino-pesquisa estabelecida acima, pois esta é a primeira disciplina do currículo a problematizar teoricamente a fronteira interdisciplinar entre História e Educação ${ }^{3}$. Tal centralidade pode ensejar investigações com viés historiográfico e viés pedagógico, sobretudo porque a ministramos na perspectiva de abordar as formas não científicas do passado histórico (CARDOSO, 2008), com ênfase na História Escolar.

Nessa abordagem centrada na investigação, o papel da avaliação se altera. Não há um conhecimento pronto em relação ao qual o professor possa medir a maior ou menor distância dos alunos. O critério avaliativo passa a ser procedimental: o quanto os estudantes conseguem, inspirado nos textos da aula e nos seus anseios pessoais, colocar uma questão à realidade, buscar respondêla com dados obtidos segundo critérios e métodos, interpretando-os à luz da

3 No atual mapa curricular do curso de Licenciatura em História da UFRB, a disciplina Ensino de História é oferecida no $5^{\circ}$ Semestre. É antecedida por Organização da Educação Brasileira (20. Sem), Didática (30. Sem) e Psicologia da Educação (40. Sem), cuja bibliografia não necessariamente passa pela problematização da especialidade. As disciplinas posteriores são dedicadas a essa ponte entre História e Educação: Metodologia do Ensino de História (60. Sem.), História da Educação no Brasil (70. Sem) e pelos Estágios Supervisionados I (observação escolar - 60. Sem), II (regência no Ensino Fundamental II - 70. Sem.) e III (regência no Ensino Médio $8^{\circ}$. Sem.). As disciplinas teóricas têm carga horária de 68 horas no semestre, e os Estágios Supervisionados 136 horas. 
questão colocada e de bibliografia de referência sobre o tema, utilizada na aula ou localizada fora dela. O que se exige é uma pesquisa no sentido científico do termo. O resultado, portanto, é desconhecido para professor e para os estudantes.

O professor incorpora o papel de orientador, no sentido que esse termo tem nas instituições acadêmicas: o indivíduo responsável por iniciar estudantes em um determinado campo de saber específico, através de indicações bibliográficas e diálogos sobre um trabalho de pesquisa em andamento. Assim, o curso de graduação deixa de ser regido por uma lógica escolar reprodutivista e passa a ser guiado por uma lógica acadêmica, voltada à produção de conhecimento individual, coletivo e socialmente significativo. Não é preciso uma iniciação científica, Trabalho de Conclusão de Curso ou pós-graduações para que tal prática comece a se realizar.

Isso significa que as aulas no ensino superior, sobretudo na área de humanas, mantém seu papel de serem espaços de discussão sobre temas centrais do componente curricular, a partir de textos-base selecionados e apresentados pelo professor ou estudantes. Mas, além disso, numa proposta de seminário, tais temas e discussões tornam-se referências possíveis para pesquisas em desenvolvimento e etapas de reflexão e problematização das investigações em curso na própria disciplina. Já a dimensão pedagógica do profissional de história é exercitada quando os resultados precisam ser comunicados para um público diversificado.

\section{Elaboração do Seminário}

Norteado por essas reflexões, passaremos a analisar o "Seminário de Ensino de História", que desde 2009 desenvolvemos na UFRB. O evento tornou-se integrante das atividades do Laboratório de Ensino de História do Recôncavo da Bahia (LEHRB), quando esse espaço foi criado, em março de 2010. A metodologia da atividade foi construída em cinco etapas: eleição do tema 
gerador, pesquisa dos alunos, registro e divulgação junto às escolas públicas / comunidade acadêmica, realização dos seminários e avaliação.

Na primeira aula, toda a turma deliberava, dialogicamente, sobre o tema geral do seminário. Sempre esclarecemos que a escolha de um único tema geral não exclui as possibilidades concorrentes, que podem ser integrados como subtemas de mesas. A vantagem ao professor universitário de atribuir às turmas a tarefa de escolher o eixo norteador do evento é avaliar, no início do curso, quais os anseios acadêmicos e sociais, as divergências e conflitos entre os alunos e os grupos que compõem as turmas, refletidos nas possibilidades levantadas e nos diálogos para a escolha. Até o presente momento, o processo de diálogo sempre resultou em um consenso de todos os alunos sobre o tema, que se tornou parte da identidade da turma por todo o semestre.

Escolhido o tema geral, a sala se dividia em equipes, responsáveis pelo trabalho de pesquisa. O assunto específico deveria ser relacionado ao tema geral do seminário e ao Ensino de História; no mais, a escolha era livre, limitada aos interesses comuns dos membros. A opção por trabalhos em equipe ocorreu pela ampliação da capacidade de leitura e busca de informações sobre um campo relativamente desconhecido dos alunos, pelo o fato de propiciar maior segurança em uma atividade pouco familiar e de maior porte, e por visar o desenvolvimento de habilidades interpessoais de trabalho em grupo (tomada de decisões, divisão de tarefas, discussão sobre os assuntos).

O módulo 1 é introdutório, no qual apresentamos a disciplina e também abordamos as várias possibilidades de pesquisa na área de Ensino de História desde os anos 1970, mapeando temas, fontes, metodologias e tendências. São introduzidas em sala de aula as principais fontes de informação acadêmica sobre Ensino de História (e sua História) como teses, artigos, livros, anais de eventos. A partir da discussão baseada nos textos de aula ${ }^{4}$, os estudantes pensam temas para o seminário a partir de seus interesses no campo. Em seguida, levados para o laboratório de informática, consultam dossiês acadêmicos sobre ensino de

40 texto de referência da aula é COSTA e OLIVEIRA, 2007. 
História cujos links estão reunidos no site do LEHRB ${ }^{5}$. Acessam o link de dois ou mais dossiês acadêmicos, leem os títulos dos artigos e escolhem ou redefinem os temas que mais os agradaram individualmente. Então, fazem uma nova consulta aos dossiês, dessa vez lendo apenas resumos dos artigos pertinentes ao tema escolhido. A atividade se repete em casa, até a totalização de dez artigos. Na aula seguinte, todos apresentam os temas que escolheram individualmente $e$ procuram afinar seus temas com os dos colegas da equipe, até chegarem a um tema comum. Depois, cada equipe consulta produções disponíveis em Teses (Banco de Teses Capes), artigos (Scielo), anais de eventos (Encontros da ANPUH, ENPEH e Perspectivas do Ensino de História). Ao longo do semestre, os estudantes deveriam articular suas escolhas com textos pesquisados nessas e em outras bases e textos das aulas regulares da disciplina "Ensino de História".

Para o desenvolvimento dos temas no seminário, foram oferecidas às equipes as seguintes possibilidades, cada uma representando um formato possível de trabalho na área: revisão bibliográfica crítica, pesquisa histórica sobre o ensino de história, pesquisa educacional sobre ensino de história, e proposta de intervenção pedagógica. Em todas, era exigido do aluno a articulação entre a bibliografia da aula e a levantada em outros meios (biblioteca, internet), com uma análise ou proposta o mais circunscrita possível, para possibilitar a abordagem em profundidade do fenômeno visado. Não houve restrição alguma sobre a escala e a localidade geográfica a trabalhar. Havia a possibilidade de orientação das equipes em horários de atendimento extraclasse, nos quais se orientava o trabalho com os textos pesquisados com a construção das categorias de pesquisa como objetivos, justificativas, referencial teórico, metodologia, fontes, resultados. Os estudantes deveriam observar a construção de tais categorias nos textos sobre o tema e a pensar uma proposta dentro das quatro linhas oferecidas.

O curso é articulado em módulos com foco nas problemáticas da relação do Ensino de História com a formação das identidades sociais, dentro e fora da

5 Dossiês Acadêmicos do LEHRB: http://www.ufrb.edu.br/lehrb/sites-apoio-ao-professor/dossiesacademicos/. 
escola. Os módulos subsequentes do curso visam, além da formação geral do estudante de licenciatura, subsidiar as pesquisas. No módulo 2 tratamos das formas e concepções de passado correntes na sociedade, focando na relação com a memória e identidades familiares ou de vizinhança, as narrativas religiosas e o tempo do capitalismo com sua concepção de progresso, em especial na atual sociedade do consumo. A justificativa desse módulo é que o professor de história frequentemente precisa lidar, em sala de aula, com concepções e modos de articulação do passado que formam a identidade dos estudantes e dos grupos aos quais pertencem.

No módulo seguinte, historiamos a história escolar e seu papel na formação das identidades desde o período jesuítico, sua disciplinarização no século XIX e XX pelo Estado Nacional interessado na formação patriótica; até a crítica dessa concepção nos anos 1980, que pautou a elaboração de currículos e livros segundo as inspirações do marxismo e da História Nova francesa. O módulo 4 prossegue a discussão segundo problemáticas recentes, tratando do ensino de história multicultural e multi-identitário, bem como relação da história com o conceito de cidadania. Por fim, terminamos o curso abordando conceitos que articulam o Ensino de História com a Pedagogia, como "cultura escolar" e "transposição didática". Tais temas estabelecem pontes diretas para a disciplina "Metodologia do Ensino da História" e para os estágios supervisionados de regência, por integrarem toda a discussão feita no semestre sob a ótica do ofício do professor em sala de aula.

No meio do semestre, enquanto as aulas se desenrolavam, ocorria a terceira etapa. As equipes entregavam o título e o resumo prévio do trabalho, a ser comentado pelo professor. Depois, professor e a turma juntavam os temas em mesas, compondo a programação do evento, que era submetida para aprovação e subsequente registro na Pró-Reitoria de Extensão. Uma vez registrada, a programação era divulgada para o público-alvo, composto por professores do ensino básico e estudantes de licenciatura, e para o público amplo, através das rádios e internet.

Uma inovação metodológica foi introduzida nos dois últimos seminários: a 
constituição de uma comissão organizadora, responsável pelo encaminhamento das atividades burocráticas, formatação da divulgação como a criação da página nas redes sociais e da arte dos cartazes, a preparação do local do evento e acompanhamento das inscrições e lista de presença. A adesão a essa comissão era sempre voluntária, e suas reuniões extraclasse adequadas à disponibilidade dos estudantes. Além disso, foi criada uma subcomissão formada por veteranos, entre os quais o monitor que disciplina passou a contar, para fazer leituras críticas dos resumos das equipes junto com o professor, sugerindo melhoras e indicações bibliográficas.

O seminário se realizava na última aula do curso, na própria universidade, com mesas de comunicação e debate. A preparação e organização das falas ficava a cargo da equipe, que deliberava se todos os membros iriam falar ou se a tarefa ficaria a cargo de uma ou duas pessoas. Todavia, durante os debates e perguntas, todos deveriam estar presentes. Os estudantes eram orientados a realizar suas apresentações em, no máximo, 20 minutos, para não interferir nas apresentações dos colegas nem no tempo reservado às perguntas e comentários, quando as equipes teriam o retorno sobre a comunicação feita. Como suporte das falas, cada equipe devia disponibilizar aos ouvintes um folder ou folha com o resumo e bibliografia sobre o tema, havendo a opção de usar projetor de slides.

Após a sessão do seminário, cada equipe se reunia com o professor para fazer uma avaliação da comunicação desenvolvida, na qual eram trocadas as impressões sobre o que foi dito, a experiência de produzir e divulgar o trabalho, bem como o que poderia ser melhorado. A discussão era centrada em cinco critérios, utilizados para compor a nota da atividade: abordagem teórica, pesquisa, folder, tempo e apresentação oral.

\section{As escolhas dos alunos}

Os eventos realizados foram: 10 Seminário: Ensino de História e Cidadania" 
(2009. $2^{6}, 12$ trabalhos), 20 Seminário: "Ensino de História e Identidade Cultural" (2010.1, 9 trabalhos), 40 Seminário: "Ensino de História e Diversidade"7 $\left(2011.2^{8}\right.$, 9 trabalhos $^{9}$ ) e $5^{0}$ Seminário: "Ensino de História: Reflexões e Práticas em Espaços Formais e Não-Formais" (2013-1, 10 trabalhos) ${ }^{10}$. A programação dos eventos segue anexa no final deste artigo ${ }^{11}$.

Uma análise das quatro programações, com total de 40 trabalhos, permite destacar:

1) A escolha dos temas gerais, feita nas primeiras aulas, e a programação mostram como as questões identitárias deram o tom da maior parte dos eventos, com exceção do último, focada nos espaços escolares, apesar de a identidade aparecer nos conteúdos das mesas. No primeiro seminário, "Cidadania", que poderia apontar perspectivas políticas mais tradicionais, tem aquele recorte bastante marcado, abordando-se pontualmente gênero e religião, pois o eixo central são as identidades locais e regionais, que foram aliadas a reflexões e perspectivas de intervenção nesse nível. No segundo evento, o foco se divide entre a questão nacional e étnico-racial, a qual é mantida no terceiro seminário, então dividindo espaço com preocupações acerca da orientação sexual, das necessidades especiais e religião (presente em todos).

Percebe-se, nos estudantes de graduação, a tentativa de lidar com um leque amplo e fragmentado de identidades numa perspectiva multicultural crítica (HALL, 2005, p. 55 e ss.), ou seja, dando atenção às especificidades e aspirações

60 evento foi realizado em janeiro de 2010 porque o semestre começou em setembro de 2009, por conta no atraso da entrega do novo prédio, o Pavilhão Leite Alves.

7 Este seminário teve modificações em relação aos anteriores, porque sua organização contou com três comissões de alunos: apoio ao evento, divulgação e acadêmica. Esta envolvia voluntariamente três alunos formandos, uma das quais monitora da disciplina, que, já tendo participado do seminário, auxiliaram no encaminhamento dos trabalhos, sugerindo temas e bibliografia, elaboração dos resumos e formas de apresentação. As outras duas eram compostas por alunos da própria turma. O evento também contou com palestras de professores da universidade e da rede pública de ensino sobre diversidade. Detalhes estão no blog do evento: ensinodhistoria.blogspot.com, acessado em 14/3/2012.

80 evento foi realizado em 5 e 6 de março de 2012 em função de duas greves no semestre, uma de servidores e outra de estudantes.

90 trabalho de Daniela Barbosa, no $4^{\circ}$ seminário, versou sobre 0 uso da informática em Cruz das Almas, não sobre charges nos livros didáticos, conforme foi divulgado.

10 O III Seminário foi realizado por outro docente que ministrou a disciplina no semestre 2010.2. Como não acompanhamos a sua realização, ele não entrará na análise.

11 Disponível em www.ufrb.edu.br/lehrb/eventos/anteriores/. Acesso em 10 março de 2014. 
de grupos historicamente marginalizados, tanto na historiografia quanto nas discussões educacionais (SILVA, 2009, capítulo 3; FONSECA e SILVA, 2007, capitulo 2), pela perspectiva dominante (branca, europeia, masculina, heterossexual, nacional, sem necessidades especiais).

Há uma sintonia com as expectativas e perspectivas atuais do sistema educacional e, particularmente, do ensino de história, questões trabalhadas na disciplina. "Cidadania", "Identidade Cultural" e "Diversidade" são grandes temas que atravessam os parâmetros curriculares, documentos oficiais e bibliografia especializada, que provavelmente chegam aos estudantes nas disciplinas anteriores da licenciatura (Organização da Educação Brasileira, Didática e Psicologia da Educação), nos eventos e outras atividades durante a graduação, além das notícias que circulam pela imprensa.

2) Sobre o formato, $63 \%$ (25) dos trabalhos estudaram a realidade educacional na atualidade, a maior parte deles sobre a região do Recôncavo Baiano; $18 \%$ (7) fizeram propostas de intervenção pedagógica, com projetos a serem desenvolvidos no Recôncavo; 13 \% (5) estudaram temas de história do ensino da disciplina ( 2 deles na região e 1 de história recente); e 8\% (3) fizeram revisão bibliográfica, todos estes no primeiro seminário.

Tabela 1 - Formato dos trabalhos

\begin{tabular}{|l|c|c|c|c|c|c|}
\hline Tipo escolhido pelas equipes & S1 & S2 & S4 & S5 & Total & \% \\
\hline Revisão Bibliográfica & 3 & 0 & 0 & 0 & $\mathbf{3}$ & $\mathbf{8}$ \\
\hline Pesquisa Histórica & 1 & 3 & 0 & 1 & $\mathbf{5}$ & $\mathbf{1 3}$ \\
\hline Pesquisa Realidade Educacional & 5 & 5 & 8 & 7 & $\mathbf{2 5}$ & $\mathbf{6 3}$ \\
\hline Intervenção Pedagógica & 3 & 1 & 1 & 2 & $\mathbf{7}$ & $\mathbf{1 8}$ \\
\hline Total & $\mathbf{1 2}$ & $\mathbf{9}$ & $\mathbf{9}$ & $\mathbf{1 0}$ & $\mathbf{4 0}$ & $\mathbf{1 0 0}$ \\
\hline
\end{tabular}

Fonte: programação dos seminários. " $S$ " significa Seminário. 


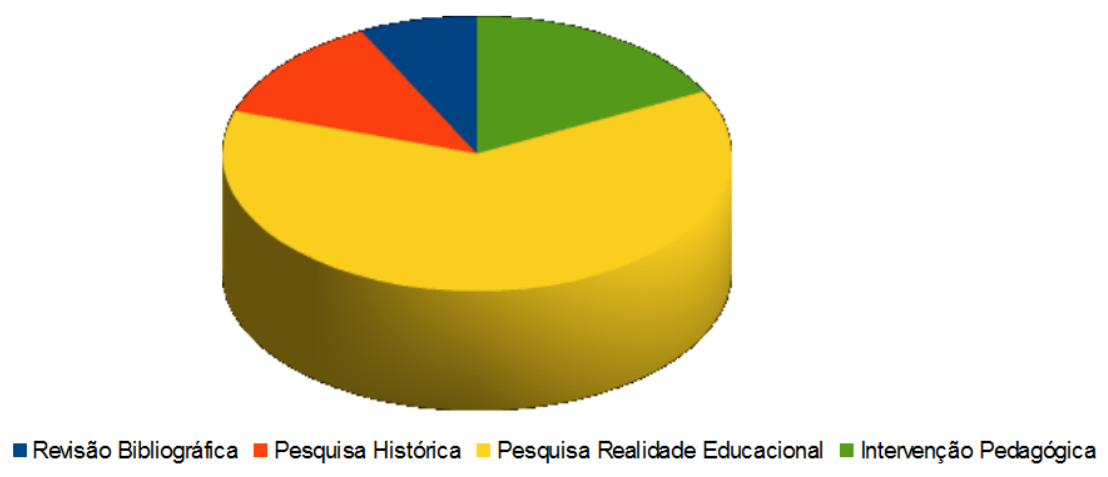

Fonte: programação dos seminários.

Os dados mostram que o encaminhamento do seminário foi marcado pelo olhar engajado dos estudantes em relação à educação. Somando as duas primeiras categorias, vemos que $81 \%$ dos trabalhos apontam para o relevo dado às questões atuais sobre ensino, dois terços deles com um enfoque analítico e um terço explicitamente visando uma intervenção.

A análise educacional numa perspectiva historiográfica foi pouco contemplada, aparecendo apenas em cinco trabalhos, três deles no segundo evento. O fato chama atenção por se tratar de um curso de História, no qual os estudantes, no $5^{\circ}$ semestre, já tiveram contato com parte do referencial teórico e metodológico da profissão. Apesar de ser uma tendência recente no campo da história, parece que os estudantes não tiveram contato com a utilização historiográfica de fontes e abordagem de objetos educacionais, não vislumbrando essa possibilidade de pesquisa. Essa informação pode ensejar reformas ou integração curricular no sentido de trabalhos conjuntos com o componente curricular "História da Educação no Brasil"

Reforça o argumento o fato de dois dos cinco trabalhos abordarem períodos (império e república) e utilizarem fontes tradicionais desse tipo de estudo (currículo e livro didático). O trabalho mais inovador abordou um período mais recuado no tempo (colônia) e utilizou uma fonte nova (um regimento escolar) de um seminário jesuítico cujas ruínas se localizam em um povoado 
próximo a Cachoeira. O trabalho histórico do quinto seminário também focou na história local, analisando a repercussão da ditadura no Ensino de História em Cachoeira valendo-se de fontes escolares e memórias de diretores, professores e estudantes do período; já aquele citado no primeiro seminário é um relato de experiência sobre a história imediata de um bairro de Salvador. Vemos, assim, a preocupação pontual com a História da educação e do Ensino de História na localidade.

3) Fica evidente no item anterior a importância geográfica, expressa na tabela abaixo:

Tabela 2 - Relação local - nacional na escolha dos temas

\begin{tabular}{|l|c|c|c|c|c|c|}
\hline Relação local - Nacional & S1 & S2 & S4 & S5 & Total & \% \\
\hline Questões Regionais e Locais & 9 & 4 & 6 & 8 & $\mathbf{2 7}$ & $\mathbf{6 8}$ \\
\hline Questões Nacionais & 3 & 5 & 2 & 2 & $\mathbf{1 2}$ & $\mathbf{3 0}$ \\
\hline Exclusivamente Metodologia & 0 & 0 & 1 & 0 & $\mathbf{1}$ & $\mathbf{3}$ \\
\hline Total & $\mathbf{1 2}$ & $\mathbf{9}$ & $\mathbf{9}$ & $\mathbf{1 0}$ & $\mathbf{4 0}$ & $\mathbf{1 0 0}$ \\
\hline
\end{tabular}

Fonte: programação dos seminários. "S" significa Seminário.

Vemos que $68 \%$ das equipes abordaram a localidade de origem dos membros da equipe, presente em três dos quatro eventos analisados. Apenas no segundo seminário a relação temas locais e nacionais foi invertida, apesar de mais equilibrada, 5 contra 4 - 56\%.

Ao analisar a programação, é preciso observar que em algumas comunicações a questão local não estava expressa no título, mas no resumo e na fala. No primeiro evento o trabalho "Religião e Ensino de História" analisou a concepção de religião de alunos de uma escola de Cachoeira e como isso refletia na sua visão de história. No evento 2, "Aprendizagem de história da África no Ensino Médio", os alunos pesquisados são de uma escola de Cruz das Almas; "A construção da identidade do aluno negro no ambiente escolar" e "Candomblé e história afro-brasileira no século XXI" focam o município de Cachoeira. No Quarto Seminário, os temas da mesa 1, o trabalho de Daniela Barbosa sobre a relação dos professores com a informática e, na mesa 3, o trabalho sobre temática indígena na sala de aula (apropriação do professor dos livros didáticos) e aquele 
sobre a construção da identidade nos terreiros. No último evento, o trabalho "História em cena: apropriação da linguagem cinematográfica pelo professor de história" analisou a apropriação dos professores dessa ferramenta, e o trabalho "Disciplina História e suas mudanças com a Ditadura Militar" abordou sua repercussão em Cachoeira.

Dentro desse aspecto, visto que a UFRB é uma universidade nova, os trabalhos possibilitaram a formação inicial de massa crítica sobre o entorno da sede, visto que metade dos trabalhos (22 de 40 - 55\%) versaram sobre Cachoeira e São Félix. O fato de a grande maioria da população ser negra coloca em relevo a questão racial, que se intensifica pela marcante presença de elementos culturais de matriz africana: a grande quantidade de terreiros de Candomblé, a Irmandade da Boa Morte, integrada apenas por mulheres negras e cujos rituais misturam elementos do catolicismo e das culturas afro-brasileiras; e pelo Samba de Roda do Recôncavo, tombado como patrimônio imaterial da humanidade pela Unesco. Além disso, as cidades vizinhas Cachoeira e São Félix possuem seu patrimonial material (histórico) nacional e internacionalmente reconhecido, com a maior parte dos imóveis da zona urbana tombados pelo IPHAN. Temas ligados à história da cidade, como patrimônio histórico, questão racial e religião, apareceram nos seminários. No primeiro evento, é priorizada a questão do patrimônio, em seus três tipos - material, imaterial e natural. Nos outros três eventos a questão cultural e racial vêm à tona, com trabalhos abordando a questão do candomblé e do ensino de história africana, afrobrasileira e indígena, estabelecendo pontos de contato entre as leis 10.639/03 e $11.645 / 08$, bastante divulgadas nos circuitos educacionais e nas licenciaturas por todo o país, e a realidade social ou escolar de Cachoeira e S. Félix.

4) A relação das aulas da disciplina "Ensino de História" na universidade com os temas dos trabalhos está expressa abaixo: 
Tabela 3: Relação dos trabalhos com assuntos das aulas

\begin{tabular}{|l|c|c|c|c|c|c|}
\hline $\begin{array}{c}\text { Relação com o assunto das } \\
\text { aulas }\end{array}$ & S1 & S2 & S4 & S5 & Total & \% \\
\hline Tema central da aula & 2 & 4 & 2 & 3 & $\mathbf{1 1}$ & $\mathbf{2 8}$ \\
\hline Subtema de aula & 3 & 4 & 6 & 5 & $\mathbf{1 8}$ & $\mathbf{4 5}$ \\
\hline Não abordado em aula & 7 & 1 & 1 & 2 & $\mathbf{1 1}$ & $\mathbf{2 8}$ \\
\hline Total & $\mathbf{1 2}$ & $\mathbf{9}$ & $\mathbf{9}$ & $\mathbf{1 0}$ & $\mathbf{4 0}$ & $\mathbf{1 0 0}$ \\
\hline
\end{tabular}

Fonte: programação dos seminários.

A tabela mostra que as apresentações que abordaram temas não tratados em aula estão majoritariamente situadas nas mesas do primeiro evento. A questão da cidadania que norteou este seminário foi tratada em aula, mas o foco dos trabalhos repousou sobre os temas específicos: história ambiental, arquivos, bibliotecas, patrimônio e papel profissional dos professores. O mesmo aconteceu em menor proporção no quarto evento, com abordagens que são assuntos da disciplina seguinte, "Metodologia do Ensino da História". Nesses casos em que o tema do seminário provém de um interesse prévio do estudante, o papel da orientação nos horários de atendimento foi preponderante. Nela, se discutia a bibliografia trazida pelo estudante e a forma de articulação com o tema geral do seminário, o que podia levar à reformulação dos assuntos. Foi o caso do estudo da OnG "Raízes do Recôncavo": para evitar redundância no estudo por uma equipe de seis pessoas, esta foi dividida em duas, cada uma focando em um aspecto do trabalho patrimonial realizado por esta organização.

O impacto das aulas parece ter sido maior no segundo Seminário, no qual todos os trabalhos abordaram um tema central ou secundário desenvolvido em sala. As apresentações da mesa 1 foram todos inspirados na aula sobre o papel da História escolar na formação da identidade nacional no Brasil; os da mesa 2 e os dois primeiros da mesa 3 na aula sobre multiculturalismo e Ensino de História, com preponderância no papel da história africana e a questão do negro. Já o trabalho sobre Ensino Jesuítico no Recôncavo é um recorte específico da aula sobre o Ensino de História no período colonial. Nos dois últimos eventos as aulas sobre o multiculturalismo e diversidade inspirou trabalhos em seus subtemas, como educação especial, homossexualidade, gênero, questão racial, educação no 
campo e história local.

É importante destacar que o foco institucional das pesquisas não foi exclusivamente o sistema escolar público. Pelo contrário, nos trabalhos vemos uma dispersão de espaços educacionais, mais evidente no primeiro evento: OnGs, bibliotecas públicas, arquivos e movimentos sociais, além de escolas particulares, investigadas sobretudo no terceiro seminário. No segundo evento, a tendência se inverte: o foco se torna o sistema escolar, apesar de aparecer um espaço religioso (terreiro de candomblé). No quarto evento, ganha destaque os trabalhos sobre educação no campo. De qualquer forma, alguns estudantes incorporaram uma tendência seguida nas aulas teóricas do curso, inspirada na Didática da História: a de abordar o ensino da história de forma socialmente ampla, considerando as diversas manifestações na sociedade, sem se restringir à educação escolar.

\section{Dificuldades e contribuições do seminário para a formação discente}

A maior parte das dificuldades da atividade foi de natureza operacional, incidindo no aspecto da extensão, principalmente da divulgação. O tempo entre o estabelecimento da programação final e a realização do evento é determinante para esse aspecto. $01^{0}$ seminário praticamente não contou com divulgação, e o público externo foi zero, enquanto o $2^{\circ}$ seminário, com o mesmo problema, teve 17 ouvintes, todos estudantes da UFRB de semestres anteriores. Nos seminários com comissão organizadora, o $5^{0}$ teve o mesmo problema de divulgação dos anteriores, pois a turma demorou a estabelecer a programação dos trabalhos finais, atrasando a divulgação para a última semana. Outros dois fatores prejudicaram esse evento: a ausência de transporte na região, que impediu o deslocamento do público, e a agenda ocupada do auditório, que deixou a única vaga para uma semana quando o semestre já havia terminado e os alunos da universidade voltam para suas residências. Por isso, o $5^{\circ}$ seminário teve 40 participantes, sendo 14 estudantes da UFRB e 36 externos, principalmente 
licenciandos de outras instituições de ensino superior privadas da região (IAENE e FAMAN).

Nesse aspecto, o maior sucesso ocorreu no $4^{0}$ seminário. Já com uma comissão organizadora estabelecida, teve tempo hábil para divulgação dos cartazes e folders, contando também com um blog e email de referência. Realizado em duas noites, teve um público de 80 pessoas em cada, sendo 31 estudantes da UFRB e o restante externo, principalmente professores da região, de Cachoeira, Cruz das Almas, Muritiba e São Félix ${ }^{12}$. Considerando a carência de transporte noturno ainda existente na região, esse número é bastante significativo da repercussão do evento.

O atraso no estabelecimento da programação é fruto de um problema ligado ao ensino de Graduação, a dificuldade dos alunos do $5^{\circ}$ semestre de História da UFRB em entender a lógica científica que leva ao estabelecimento de um tema, seus recortes, objetivos, fontes e metodologia de pesquisa. Isso, em parte, é fruto da ausência no mapa curricular do curso de um componente curricular de "Introdução aos Estudos Acadêmicos" ou "Metodologia da Pesquisa Científica". Tanto que, no início do componente curricular, passamos a dedicar uma ou duas aulas, conforme a turma, para uma introdução ao tema, mapeamento das bases de dados acadêmicas com artigos e teses sobre ensino de História, e exercícios de identificação e formulação das categorias de pesquisa. Ainda assim, mesmo após as orientações, notamos a demora das equipes em incorporar a lógica envolvida nesse processo, que às vezes se revelava no dia do evento. Por recomendação dos próprios alunos, insegura quanto a isso, no último seminário foi realizado um ensaio na aula, onde a própria turma pode tecer críticas aos trabalhos visando aparar problemas a serem corrigidos para o evento.

É nesse ponto de iniciação à pesquisa que repousa a maior contribuição da atividade para os alunos. Alguns deles relataram oralmente ao docente da disciplina que, mesmo em equipe, esta foi a primeira experiência de pesquisa sobre tema de própria escolha, organização de evento e apresentação oral além

12 Esses números são baseados nas listas de presença dos eventos remetidas à pró-reitoria de extensão, para confecção dos certificados. Recebiam os certificados aqueles com $75 \%$ de frequência. 
da sala de aula. Os relatos apontam o potencial das disciplinas da graduação de iniciar o estudante em outras dimensões da vida acadêmica e profissional. Afinal, o estudante teve a oportunidade de exercitar a prática de questionar a realidade educacional no que se refere ao ensino da história, formular um problema e suas hipóteses, estabelecer objetivos, métodos, diálogos com a bibliografia para refletir sobre os resultados e chegar a conclusões, mesmo que parciais e restritas. Se a turma toda se familiariza com a metodologia da pesquisa, abre-se e legitima-se a possibilidade de um olhar científico sobre a educação histórica, que poderão germinar em momentos posteriores da graduação ou mesmo durante a vida profissional do futuro professor.

Por exemplo, dois dos trabalhos apresentados nos dois primeiros seminários foram voluntariamente encaminhados e aceitos em outro evento na universidade, um encontro de História realizado pelo próprio colegiado ${ }^{13}$; um trabalho do IV Seminário foi encaminhado e aceito em um simpósio de uma instituição externa ${ }^{14}$; e outros 4 trabalhos, distintos destes, deram origem a Trabalhos de Conclusão de Curso (TCCs) ${ }^{15}$. Considerando que as três primeiras turmas adentraram num curso de bacharelado e tiveram uma formação voltada à pesquisa em história, o curso sensibilizou alguns estudantes para a possibilidade de pesquisa acadêmica em educação e ensino. O mesmo pode ser dito das turmas já licenciandas, nas quais duas pessoas desejam prosseguir no tema apresentado no seminário. Isso mostra a importância de fomentar a pesquisa nas disciplinas de graduação, subsidiando os temas na área de Ensino de História.

13 I Encontro de História do CAHL: Abordagens e Perspectivas. Realizado de 18 a 21 de outubro de 2010. A mesa foi "Educação e Ensino de História", que coordenamos. A lista dos trabalhos da mesa pode ser visualizada em http://www.ufrb.edu.br/lehrb/2010/10/13/mesas-de-educacao-eensino-de-historia-no-i-encontro-de-historia-do-cahl/, acesso em 09.fev.2012.

14 A comunicação "Silêncio, Omissões e Imprecisões: a temática homossexualidade e o ensino de História" integrou a mesa de educação do VI encontro de História: Historia e Linguagens: Dominios e Diálogos, realizado pelo departamento de História - Uneb Caetité, 2012. Disponível em http://www.historiavi.uneb.br/v/index.php/noticias/34-educacao. Acesso em 5 mai 2012.

15 Os trabalhos gerados foram: Elaboração de um currículo de História Local: São Félix, que incorporou o trabalho do estudante sobre o papel do arquivo municipal da cidade; o trabalho sobre a Educação Jesuítica no Seminário de Belém de Cachoeira; o trabalho sobre a repercussão da Ditadura Militar no Ensino de História em Cachoeira e o trabalho sobre a relação dos professores com a informática, ambos ainda em andamento. 
Na questão profissional, o aluno envolveu-se com dimensões da realidade escolar, passada ou presente, como a legislação, os materiais didáticos em suas múltiplas dimensões, a escola, a sala de aula e seus principais atores, professores e alunos. A reflexão sobre a prática da educação histórica aproxima esta disciplina teórica dos Estágios Supervisionados, sendo estes os momentos onde os estudantes observarão e protagonizarão situações de docência, sobre as quais espera-se reflexões à luz da bibliografia do curso de Licenciatura.

O aspecto da extensão foi importante porque incitou na turma sentidos que iam além da apresentação para o professor e para os colegas de sala, típicas dos seminários de graduação. Com o objetivo de ensejar maior responsabilidade e engajamento, agregava uma motivação social à relação entre sujeito e objeto na pesquisa, pois tiveram que considerar o público-alvo. Ao mesmo tempo, falar para pessoas desconhecidas, da universidade e fora dela, levava a um trabalho do estudante sobre a própria ansiedade, medos, insegurança, nervosismo, ou seja, um olhar para as próprias emoções e suas manifestações, envolvidas na comunicação em eventos para grande número de pessoas. Superar esse desafio de se postar em público foi um dos pontos mais recorrentes relatados pela maior parte dos alunos.

A apresentação destinada a um público amplo também exigiu um cuidado com a comunicação oral, aspecto central da docência. A avaliação dessa dimensão deixou os estudantes apreensivos, mas foi considerada positiva quando ouviram nossas impressões sobre os aspectos formais, como a velocidade da fala, clareza, tom de voz, olhar, gestos, linguagem, uso do datashow e o cumprimento do tempo estipulado. Como uma reunião foi feita com cada equipe, os colegas contribuíram com suas próprias percepções, tornando a avaliação sobre a apresentação um processo coletivo.

\section{Considerações finais}

A tendência geral dos estudantes foi valer-se da atividade de pesquisa na 
disciplina de graduação para subsidiar investigações pontuais sobre algum aspecto educacional da realidade próxima. Isso foi evidenciado na escolha dos temas, com a seleção de problemas tendo em vista a análise de suas manifestações locais, e nos formatos que priorizaram aspectos atuais da educação e projetos de intervenção. Isso motivou os estudantes e deu sentido à aprendizagem dos temas de ensino de história. Longe de ser um fim em si, a aula de "Ensino de História" tornou-se parte de um todo que incluía a subjetividade do aluno, a pesquisa orientada sobre a localidade e o retorno do saber à comunidade, via seminário, projeto de intervenção, artigo para comunicação ou TCC. A aprendizagem acadêmica foi modificada substancialmente pela integração da aula de graduação às dimensões da pesquisa e extensão universitárias.

\section{Referências}

AZEVEDO, C. B. História e Investigação na Escola. Acesso: 16 de março de 2012, disponível em:

http://sedeh.webnode.com.br/historia\%20e\%20investiga\%C3\%A7\%C3\%A30\%2 ona\%20escola/.

. História e Investigação na Escola: a experiência de formação do

professor-pesquisador. História \& Ensino, Londrina, v. 2, n. 17, jul-dez/2011, p. 339-359. Disponível em

http://www.uel.br/revistas/uel/index.php/histensino/article/view/11245/10013, acesso: 9.jul.2012.

CARDOSO, O. Para uma definição de Didática da História. Revista Brasileira de História. São Paulo, v. 28, n. 55, 2008, p. 153-170. Acesso em 14 de março de 2012, disponível em: http://www.scielo.br/pdf/rbh/v28n55/a08v28n55.pdf.

COSTA, A. L.; OLIVEIRA, M. M. D. O Ensino de História como objeto de pesquisa no Brasil. Saeculum. Revista de História, v. 16, João Pessoa, jan/jun. 2007, p. 147-160. Disponível em www.cchla.ufpb.br/saeculum/saeculum16 art04 costaoliveira.pdf.

FONSECA, S. G.; SILVA, M. Ensinar História no Século XXI: em busca do tempo entendido. Campinas: Papirus, 2007. 
HALL, S. Da Diáspora: identidades e mediações culturais. Belo Horizonte: UFMG; Brasília: Unesco, 2003.

NEVES, J. A Graduação em História: etapa do ensino de história voltada para a formação do professor/pesquisador. In: ARIAS NETO, José Miguel (Org.). Dez Anos de Pesquisa de Ensino de História. VI Encontro de Pesquisadores de Ensino de História. Londrina: Atrito Art, 2005.

SANTOS, B. S. Pela Mão de Alice: o social e o político na pós-modernidade. 7a. ed. Porto: Afrontamento, 1999 (1994), p. 163-201.

SILVA, T. T. Documentos de Identidade: uma introdução às teorias de currículo. 3 ed. Belo Horizonte: Autêntica, 2009.

Recebido em 21 de outubro de 2014

Aprovado em 10 de junho de 2015. 


\section{Anexos: Programação dos Eventos}

A) Primeiro Seminário

\section{Seminário: Ensino de História e Cidadania \\ 22 de janeiro de 2010 - 13:00 às 19:00 \\ Sala de Reuniões CAHL/UFRB}

\begin{tabular}{|c|c|c|}
\hline $13: 30$ & $13: 50$ & $\begin{array}{c}\text { Gênero, Ensino de História e Cidadania } \\
\text { Ana Paula Batista, Edilon de Freitas, Silvana Rocha, Gabriela Carvalho }\end{array}$ \\
\hline $13: 50$ & $14: 10$ & $\begin{array}{l}\text { Religião e Ensino de História } \\
\text { Camila Vieira, José Luis Sacramento, Leonardo Guimaräes Leite }\end{array}$ \\
\hline $14: 10$ & $14: 30$ & $\begin{array}{c}\text { História Regional e Local no Ensino } \\
\text { Larissa de Oliveira. Thalita Ferraz }\end{array}$ \\
\hline $14: 30$ & $14: 45$ & Debates \\
\hline \multicolumn{3}{|c|}{ Mesa 2 - Formação da Cidadania através do Ensine de História } \\
\hline $14: 45$ & 15:05 & $\begin{array}{c}\text { A responsabilidade profissional do professor de história } \\
\text { Adriano Batista, Heber Femandes, Rodrigo Nascimento }\end{array}$ \\
\hline $15: 05$ & $15: 25$ & $\begin{array}{c}\text { A cidadania como norteadora do ensino de História: uma } \\
\text { proposta curricular } \\
\text { Alexsandro, Augusto Fagundes, Joäo Paulo, Márcio Oliveira, Cláudio França, } \\
\text { Joana Souza }\end{array}$ \\
\hline $15: 25$ & $15: 45$ & $\begin{array}{c}\text { História, movimento social, identidade e cidadania: o } \\
\text { movimento "Volta Beiru" (Salvador - 2005) } \\
\text { Clissio Santana }\end{array}$ \\
\hline $15: 45$ & $16: 00$ & Debates \\
\hline \multicolumn{3}{|r|}{ Intervalo } \\
\hline \multicolumn{3}{|c|}{ Mesa 3 - Espaços não-escolares de Ensino de História: Propostas } \\
\hline $16: 20$ & $16: 40$ & $\begin{array}{c}\text { O Paraguaçu: proposta de ensino de História ambiental } \\
\text { Gleiciane Damasœeno, Nadja Lage, Lara Lima }\end{array}$ \\
\hline $16: 40$ & $17: 00$ & $\begin{array}{c}\text { Biblioteca pública como espaço de cidadania em Cachoeira } \\
\text { Ana Paula Albuquerque, Gabriel Cordeiro, Uelton Rocha }\end{array}$ \\
\hline $17: 00$ & $17: 20$ & $\begin{array}{l}\text { Arquivo Público e ensino de História: formação da cidadania } \\
\text { em S. Felix } \\
\text { Rodrigo Araújo Paixão }\end{array}$ \\
\hline $17: 20$ & $17: 35$ & Debates \\
\hline \multicolumn{3}{|r|}{ Mesa 4 - Patrimônio e Ensino de História no Recôncavo } \\
\hline $17: 35$ & 18:05 & $\begin{array}{c}\text { Patrimônio Material na ONG "Raízes do Recôncavo" } \\
\text { Ana Paula Lessa, Genilson Neri, Melira Elen } \\
\end{array}$ \\
\hline $18: 05$ & $18: 25$ & $\begin{array}{l}\text { A ONG "Raízes do Recôncavo" e o patrimônio imaterial } \\
\text { Josy Barcellos, Maria da Conceicảo, Nara Falcón }\end{array}$ \\
\hline $18: 25$ & $18: 45$ & $\begin{array}{c}\text { A noção de patrimônio dos alunos em São Félix } \\
\text { Alesandra Regis do Rosário. Darlane Silva Senhorinho }\end{array}$ \\
\hline $18: 45$ & 19:00 & Debates \\
\hline
\end{tabular}


B- Segundo Seminário

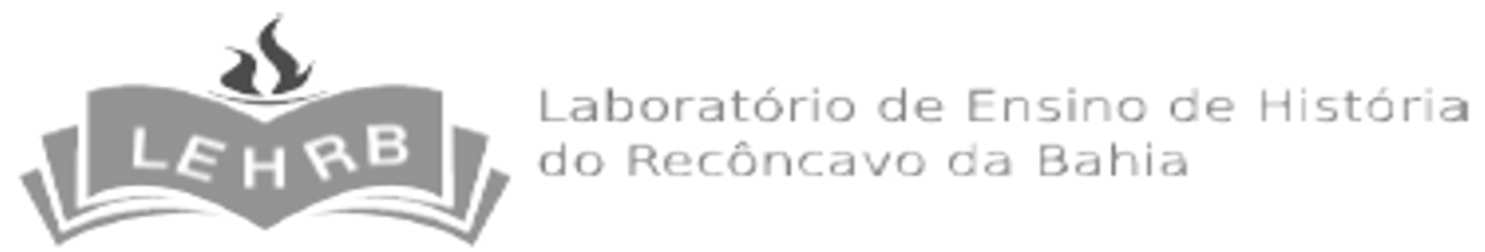

II Seminário de Ensino de História

Ensino de História e Identidade Cultural

13 de julho de 2010 - Sala Reuniões - CAHL/UFRB

Abertura

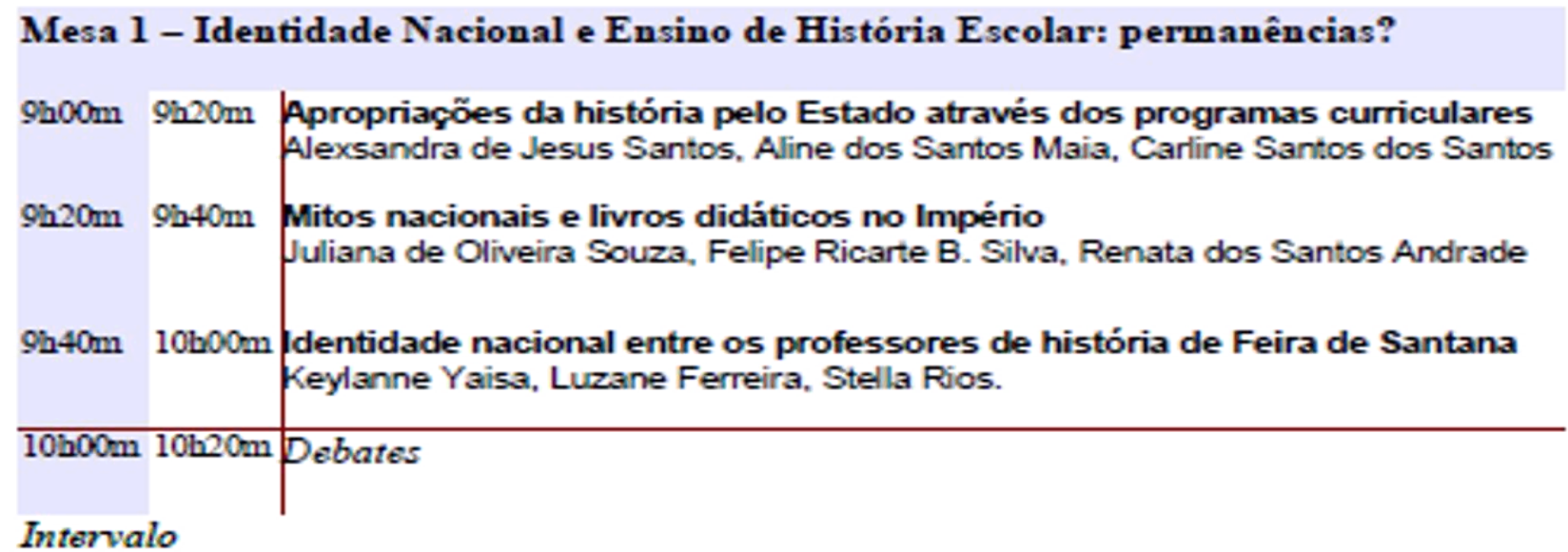

Mesa 2 - A África é longe daqui? Ensino de História da África e Cultura afrobrasileira

$10 \mathrm{~h} 30 \mathrm{~m} 10 \mathrm{~h} 50 \mathrm{~m}$ Aprendizagem de História da África no Ensino Médio

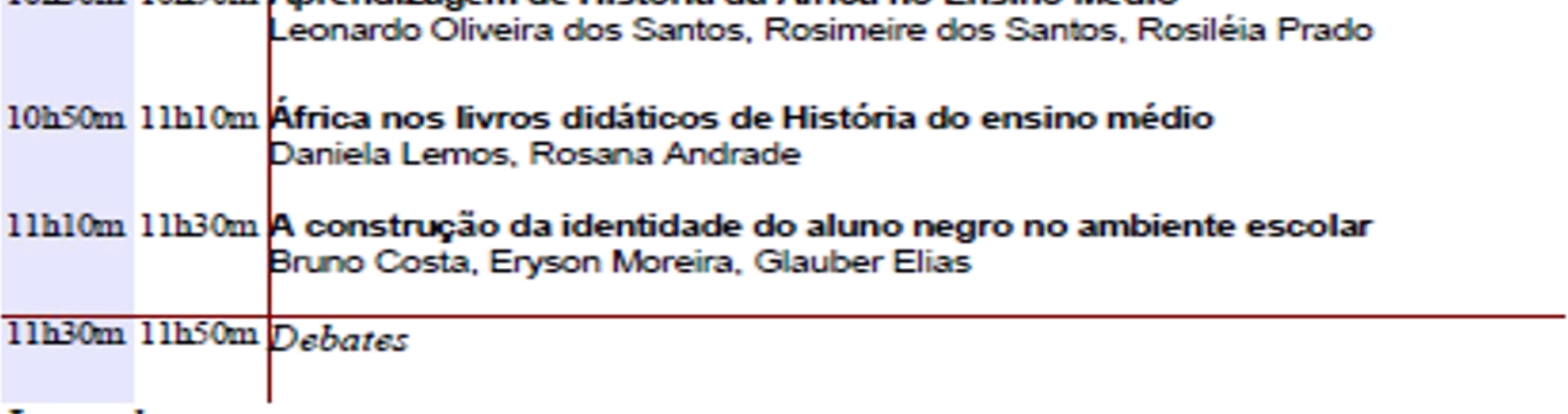

Intervalo

Mesa 3 - Religiosidades e culturas no Ensino da História: entre passado e presente

$12 \mathrm{~h} 00 \mathrm{~m} 12 \mathrm{~h} 20 \mathrm{~m}$ Candomblé e história afro-brasileira no século XXI

Edvaldo Nascimento, Jadson Ferreira dos Santos, Marcelo Azevedo

$12 \mathrm{~h} 20 \mathrm{~m} 12 \mathrm{~b} 40 \mathrm{~m}$ Questões indigenas no contexto escolar: uma proposta de ensino

Jamille Macedo, Rosana da Silva Ferreira, Willys Bezerra

$12 \mathrm{~h} 40 \mathrm{~m}$ 13h00m Educaçäo Jesuítica no Recôncavo da Bahia

Alfredo Júnior, Antonio Modesto e Robson Matos 


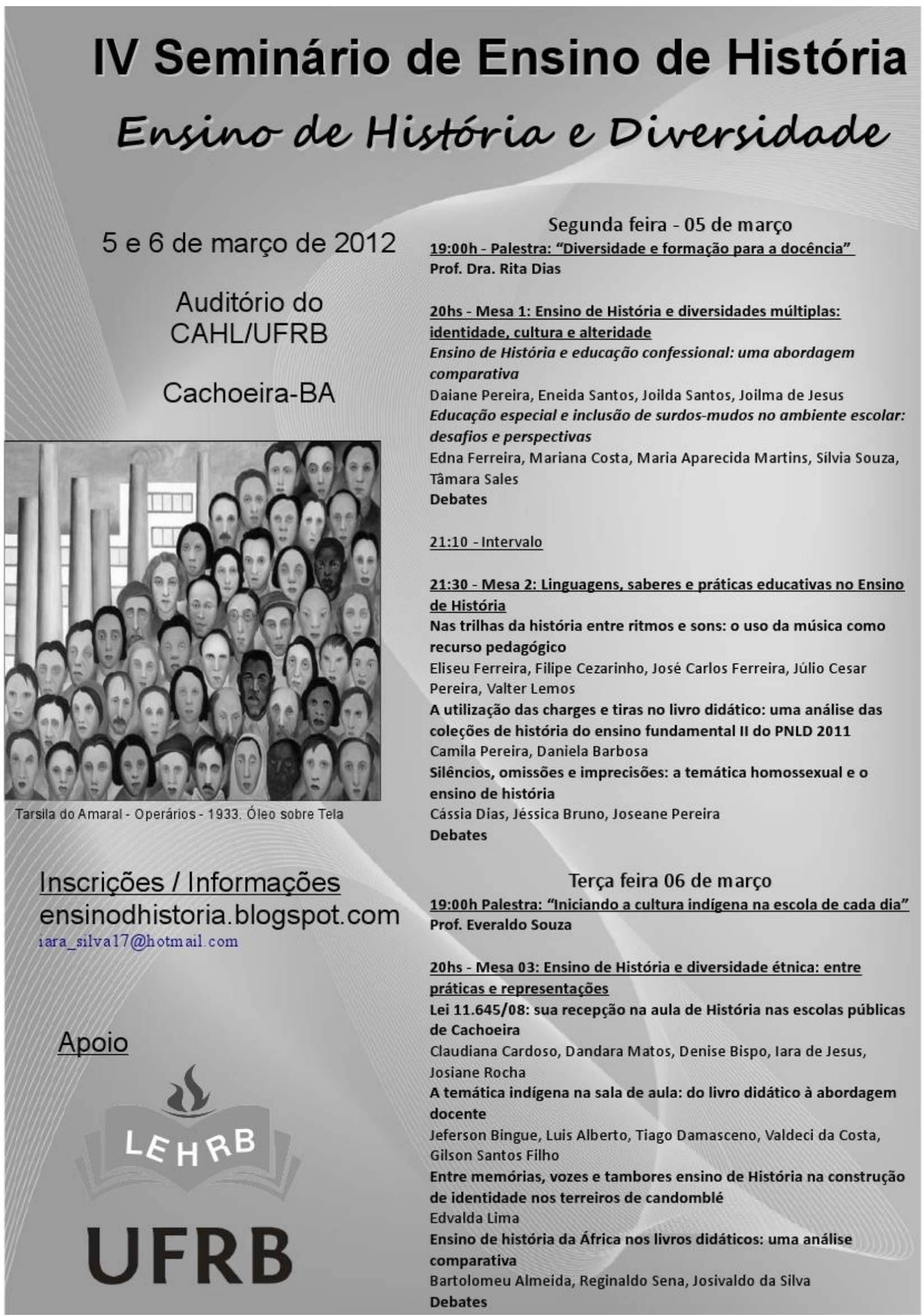


D- Quinto Seminário

V Seminário de Ensino de História: Ensino de História: Reflexões e práticas em espaços formais e não formais - 29 de outubro 2013 Auditório - CAHL/UFRB

Mesa 1:

\section{Tarde}

\begin{tabular}{|l|l|}
\hline $15 \mathrm{~h} 00 \mathrm{~m}-$ & $\begin{array}{l}\text { Concepções docentes sobre o Ensino de História e Cultura } \\
\text { afro-brasileira no Ensino Fundamental I: uma análise das } \\
\text { práticas pedagógicas do Centro Educacional Batista em } \\
\text { Muritiba } \\
\text { Alexandro Monteiro, Edilene Santos, Elisangela Teixeira }\end{array}$ \\
\hline $\begin{array}{l}15 \mathrm{~h} 20 \mathrm{~m}- \\
15 \mathrm{~h} 40 \mathrm{~m}\end{array}$ & $\begin{array}{l}\text { O Ensino de História nos Assentamentos do MST de Santo } \\
\text { Amaro } \\
\text { Pablo Rezende e Ludimila Maria Araújo }\end{array}$ \\
\hline $\begin{array}{l}15 \mathrm{~h} 40 \mathrm{~m}- \\
16 \mathrm{~h} 00 \mathrm{~m}\end{array}$ & $\begin{array}{l}\text { Educação no Campo: Perspectivas e vivências pedagógicas } \\
\text { na escola municipal Otávio Pereira, Tabuleiro da Vitória, } \\
\text { distrito de Cachoeira } \\
\text { Adenizia Santos, Bárbara Driele, Marilene Pinto }\end{array}$ \\
\hline $\begin{array}{l}\text { 16h00m - } \\
16 \mathrm{~h} 30 \mathrm{~m}\end{array}$ & \begin{tabular}{l} 
Debates \\
\hline
\end{tabular}
\end{tabular}

Intervalo - (20 min.)

Mesa 2:

\begin{tabular}{|l|l|}
\hline $\begin{array}{l}16 \mathrm{~h} 50 \mathrm{~m}- \\
17 \mathrm{~h} 10 \mathrm{~m}\end{array}$ & $\begin{array}{l}\text { A trilha sonora da ditadura militar: uma possibilidade } \\
\text { didático pedagógica na representação dos aspectos } \\
\text { histórico-sociais do Brasil na década de } \mathbf{1 9 6 0} \\
\text { Tamires Teles e Shirley Melo }\end{array}$ \\
\hline $\begin{array}{l}17 \mathrm{~h} 10 \mathrm{~m}- \\
17 \mathrm{~h} 30 \mathrm{~m}\end{array}$ & $\begin{array}{l}\text { História em cena: apropriação da linguagem } \\
\text { cinematográfica pelo professor de história } \\
\text { Joilson Fiuza, Verônica Silva e Reijane Reis }\end{array}$ \\
\hline $\begin{array}{l}17 \mathrm{~h} 30 \mathrm{~m}- \\
18 \mathrm{~h} 00 \mathrm{~m}\end{array}$ & Debates \\
\hline
\end{tabular}

Mesa 3:

Noite

\begin{tabular}{|l|l|}
\hline $\begin{array}{l}19 \mathrm{~h} 30 \mathrm{~m}- \\
19 \mathrm{~h} 50 \mathrm{~m}\end{array}$ & $\begin{array}{l}\text { Ensino de História: Questão de gênero e sexualidade (PCNs) } \\
\text { Sulamita Lima, Emanuela Ramos, Erica Marques }\end{array}$ \\
\hline $\begin{array}{l}\text { 19h50m - } \\
20 \mathrm{~h} 10 \mathrm{~m}\end{array}$ & $\begin{array}{l}\text { Minha História: um diálogo da pedagogia libertária e o } \\
\text { ensino de História Local } \\
\text { Carlos Augusto, Cláudio Azevedo }\end{array}$ \\
\hline $20 \mathrm{~h} 10 \mathrm{~m}-$ & Disciplina História e suas mudanças com a Ditadura Militar \\
\hline
\end{tabular}




\begin{tabular}{|l|l|}
\hline $20 \mathrm{~h} 30 \mathrm{~m}$ & Inaiam Lobo, Judite Ferreira, Verena Pereira \\
\hline $20 \mathrm{~h} 30 \mathrm{~m}-$ & Debates \\
$21 \mathrm{~h} 00 \mathrm{~m}$ & \\
\hline
\end{tabular}

Intervalo - (20 min.)

Mesa 4:

\begin{tabular}{|l|l|}
\hline $\begin{array}{l}21 \mathrm{~h} 20 \mathrm{~m}- \\
21 \mathrm{~h} 40 \mathrm{~m}\end{array}$ & $\begin{array}{l}\text { Aulas de História em Escolas religiosas: Problemas, } \\
\text { dificuldades e perspectivas da História religiosa em dois } \\
\text { colégios confessionais } \\
\text { Antonio dos Santos Ribeiro }\end{array}$ \\
\hline $\begin{array}{l}21 \mathrm{~h} 40 \mathrm{~m}- \\
22 \mathrm{~h} 00 \mathrm{~m}\end{array}$ & $\begin{array}{l}\text { Compreensão do conceito de escravidão por alunos da } \\
\text { escola pública de Cachoeira } \\
\text { Leonardo Rocha e Gustavo Santana }\end{array}$ \\
\hline $\begin{array}{l}22 \mathrm{~h} 00 \mathrm{~m}- \\
22 \mathrm{~h} 30 \mathrm{~m}\end{array}$ & Debates \\
\hline
\end{tabular}

